\title{
EL MORALISMO LEGAL CONTRAATACA
}

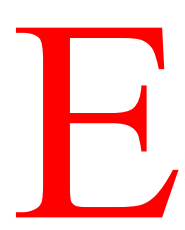

1 reciente debate que se ha producido en España sobre los contenidos morales que deben incluir u omitir los espacios televisivos a raíz de la proliferación de los llamados «reality shows» ha puesto de relieve, de nuevo, la importancia del problema del moralismo legal*. Hace tiempo, la ya clásica polémica entre Devlin

y Hart marcó los límites y el alcance de la discusión, a partir del «Wolfenden Report», aunque con un objetivo diferente. En este breve artículo quiero volver a poner de manifiesto la importancia de aquel debate y su posible utilidad en nuestros días.

En las últimas décadas se ha escrito mucho acerca del papel que juega el Derecho en el mantenimiento de las pautas morales de una comunidad. En el ámbito anglosajón, como es bien sabido, la comisión creada en 1954 bajo la dirección de John Wolfenden en Inglaterra para investigar el estado de las leyes penales sobre la homosexualidad y la prostitución presentó al gobierno británico un conocido informe en 1957 («Wolfenden Report»1). Dos años más tarde, un prestigioso jurista, Patrick Devlin, juez del Queen's Bench y posteriormente miembro de la Cámara de los Lores, después de una primera identificación con la tesis mantenidas por el informe «Wolfenden» pronunció una conferencia en la British Academy titulada «The Enforcement of Morals» ${ }^{2}$, en donde puso de manifiesto, de manera argumentada, su discrepancia. La más completa respuesta a Devlin se encuentra en el libro del profesor Hart, «Law, Liberty and Morality ${ }^{3}$.

* Llamaré «moralismo legal» a la tesis que sostiene que la opinión moral de la mayoría es fundamento suficiente para dar contenido a las normas jurídicas.

1 Wolfenden Report. Authorized American ed. New York: Lancer Books. Report of the Departamental Comittee en Homosexual Offences and Prostitution, 1957 (1964).

${ }^{2}$ «The Enforcement of Morals», Oxford Univ. Press, 1965.

${ }^{3}$ Stanford Univ. Press, 1963. 
La historia del debate se puede retrotraer al siglo pasado con motivo de la publicación del ensayo de J. Stuart Mill, On Liberty (1859) y la airada respuesta que formuló el conocido abogado y jurista James Fitajames Stephen en un libro titulado "Liberty, Equality, Fraternity», publicado originalmente en 1873, justo antes de la muerte de Mill ${ }^{4}$. La tesis de Devlin tienen cierto aire de familia con las tesis de Stephen, mientras que Hart se acerca a las tesis de Mill que retoma el informe Wolfenden: la idea de que existe un ámbito de la conducta privada en el que ni la sociedad ni el Derecho deberían intervenir.

Resumiré brevemente los argumentos presentados por el informe Wolfenden, Devlin y Hart, con el fin de indagar la tesis del moralismo legal y su crítica.

\section{I}

\section{El informe Wolfenden}

El principio sobre el que construye Mill toda la estrategia argumentativa de "On Liberty» se pone de manifiesto de forma precisa en el siguiente texto:

«...el único fin para el que el género humano está autorizado, individual o colectivamente a interferir en la libertad de acción de cualquiera de sus miembros es la propia protección. Que el único propósito con el que el poder pueda ser legítimamente ejercido sobre cualquier miembro de una comunidad civilizada contra su voluntad es para prevenir el daño a otros. No puede ser legítimamente compelido a hacer u omitir algo porque ello sea mejor para él, porque le vaya a hacer más feliz, porque, en la opinión de otros, hacerlo fuere sabio o incluso moralmente correcto» ${ }^{5}$.

El denominado «moralismo legal» viene a sostener que las normas jurídicas deben incorporar las pautas de la moral positiva, esto es, las creencias morales de la mayoría social. La opinión moral de la mayoría debe ser reforzada jurídicamente, de modo que sus contenidos pueden ser protegidos mediante la imposición coactiva. Mill piensa que las creencias morales mayoritarias pueden ser razones a tener en cuenta en el curso de nuestra propia conducta, pero su papel

\footnotetext{
${ }^{4}$ Mill murió en el mismo año. Stephen, J. F. 1967. Liberty, Equality, Fraternity. Ed. por R. J. White. Ed. original de 1873. Cambridge Univ. Press.

${ }^{5}$ J. S. Mill, «Sobre la libertad», Alianza Ed., 1970. El subrayado es mío.
} 
se limita a la persuasión, no a la coacción, salvo que nuestra conducta personal perjudique a los demás.

Mill divide las acciones en dos grupos: acciones autorreferentes y acciones que afecten a la sociedad. Su principio se basa en esta difícil distinción de grado. La sociedad puede interferir la conducta que perjudica a sus miembros en el ejercicio de sus derechos, por la acción de terceros, a imponer coactivamente el ejercicio de un deber social a quien, por omisión, incumple tal prestación. Incluso la sociedad puede sancionar mediante la crítica pública las conductas que considera antisociales, aunque no perjudiquen directamente los derechos. Lo que no puede hacer es interferir coactivamente el ámbito de la libertad individual que cada uno tiene cuando lleva a cabo acciones autorreferentes. Como dice el propio Mill, «sobre sí mismo, sobre su propio cuerpo y espíritu, el individuo es soberano».

Dos ejemplos típicos pueden ayudarnos a comprender el alcance de este principio: el alcoholismo y las relaciones sexuales. El primero no daña a terceros, y, por tanto, no debe sancionarse legalmente. Se pueden imponer sanciones jurídicas a quienes. como consecuencia del abuso de alcohol, transgreden el ordenamiento jurídico. Pero no todos los alcohólicos lo hacen, de manera que el tipo delictivo no debe confundirse con esa conducta autorreferente. Si un alcohólico incumple sus deberes familiares será responsable jurídicamente por sus omisiones, no por su aficiones. En el ámbito de las relaciones sexuales sucede algo similar: el principio de Mill debe tolerar todas las conductas sexuales heterodoxas libres mantenidas entre adultos. Otra cosa es que se transgredan en su ejercicio los derechos de otras personas ${ }^{6}$.

El informe Wolfenden coincide esencialmente con las tesis de Mill. La comisión se creó para investigar el estado de las leyes penales sobre la homosexualidad y la prostitución. En su opinión, la función del Derecho Penal en este ámbito consiste en preservar el orden público y proteger a los ciudadanos de lo que es ofensivo e injurioso, especialmente a quienes son más vulnerables porque son jóvenes, débiles, físicos o mentales, inexpertos y dependientes. Sólo las acciones inmorales que perjudican a terceros deben producir sanciones jurídicas, aunque el carácter ofensivo e indecente de algunas prácticas sexuales públicas pueden servir de base para la coerción. Ahora bien, del hecho de que la sociedad condene moralmente determinadas conductas no se deriva la justificación de su prohibición o sanción legal. La moralidad o inmoralidad privada no es asunto del Derecho. De manera que las prácticas homosexuales entre adultos que consienten no debían ser consideradas delito, al igual que la

${ }^{6}$ Los dos ejemplos los propone M. D. Bayles, «Hart's Legal Philosophy», Klower Academic Publishers, 1992, pág. 193. 
práctica de la prostitución -aunque debieran llevarse a cabo fuera de lugares públicos.

II

\section{La crítica de Devlin}

Lord Devlin criticó la resolución del comité Wolfenden, arguyendo -como hiciera Lord Stephen contra Mill- que «la supresión del vicio es asunto que concierne al Derecho tanto como la supresión de las actividades subversivas». Devlin sostiene que, aunque no debiera ser siempre así, la sociedad tiene derecho a imponer coactivamente su moral social. La legislación, según este punto de vista, no tiene límites teóricos en la imposición de la moral, sólo tiene algunas limitaciones prácticas.

El núcleo de argumentación de Devlin se apoya en la falta de coherencia que el informe tiene respecto al Derecho inglés. En primer lugar, en contra del principio que sostiene el informe Wolfenden, el consentimiento de la víctima no es un elemento que exima de responsabilidad jurídica, salvo en los casos cuya ausencia forme parte constitutiva del tipo, como la violación. Para Devlin, la transgresión de determinados comportamientos no debe entenderse como una agresión personal contra las posibles víctimas, sino como una conducta que produce un daño social. Además, en segundo lugar, hay delitos cometidos en privado y con consentimiento que aunque no ofenden, ni explotan, ni corrompen ni dañan a otros, persisten como tales en el Derecho inglés: tales son la eutanasia, el suicidio, el duelo, el aborto y el incesto. De manera que aquí, como en la celebración de contratos con fines inmorales, el Derecho actúa como un factor de protección moral social, y no como un simple garante de los derechos de las personas. Por consiguiente, como el Derecho penal está basado en principios morales y su función va más allá de la imputada por el informe Wolfenden, la argumentación del citado informe es contradictoria: no mide con la misma vara los contenidos morales que se encuentran en el código penal. Si se promueve la despenalización de la prostitución y de la homosexualidad, entonces también se deberían despenalizar otras conductas tipificadas como delitos en el Derecho penal y que reúnen las mismas características que las conductas mencionadas.

Resumiré los pasos de su argumentación ${ }^{7}$ :

${ }^{7}$ Sigo la exposición que hace Bayles en «Hart’s Legal Philosophy», op. cit., pág. 195 y ss. 
1. La moral pública, entendida como las creencias morales mayoritarias de una determinada comunidad, es un hecho social. La sociedad es un conjunto de personas que comparten una comunidad de ideas.

2. La sociedad tiene derecho a imponer coactivamente esta moral mediante el Derecho, siempre que se den cuatro principios o circunstancias.

2.1. La sociedad debe hacer compatible el máximo grado de libertad con la mayor integridad o unidad social.

2.2. El legislador debe ser consciente de los cambios de mentalidad respecto de la moral, y debe ajustarse a ellos.

2.3. La intimidad debe respetarse tanto como sea posible, en el sentido de no facilitar información acerca de una persona ${ }^{8}$.

2.4. El Derecho debe garantizar una moral de mínimos, no de máximos.

La defensa de la moral se identifica con la defensa de la sociedad del mismo modo que la traición es un ataque a la integridad social, las conductas inmorales deben ser rechazadas porque pueden producir un daño social.

3. La moral social se puede identificar como la moral del «hombre de la calle», aunque los sentimientos de tolerancia e indignación «razonables» no son suficientes para legislar.

En resumen: Devlin rechaza el punto de vista liberal -defendido por Mill y el informe Wolfenden- del principio del daño a terceros. En lugar de ello sostiene que la sociedad tiene derecho a legislar contra cualquier conducta inmoral que dañe a su integridad social; como la sociedad es un conjunto de creencias morales compartidas, cualquier conducta que afecte a la moral social puede ser entendida como una agresión social. Aunque la sociedad tiene derecho a prohibir tales conductas Devlin advierte que el Derecho versa sobre mínimos morales, que los límites de la tolerancia cambian y que la libertad y la intimidad tiene mucho valor.

\footnotetext{
${ }^{8}$ Es sabido que en nuestro Ordenamiento jurídico la libertad de información prevalece siempre sobre el derecho a la intimidad y el honor siempre que la información sea veraz y que su contenido «se desenvuelva en el marco del interés general del asunto al que se refiere: de otra forma, el derecho de información se convertiría en una cobertura formal para, excediendo el discurso público en el que debe desenvolverse, atentar sin límite alguno y con abuso del derecho al honor y la intimidad de las personas, con afirmaciones, expresiones o valoraciones que resulten injusti-
} 
La tesis de Devlin no debe confundirse con argumentos más radicales o clásicos acerca del moralismo legal. Devlin no sostiene que el deber del Estado sea hacer a la gente moralmente buena, para cuyo propósito debe hacer cumplir la moral positiva; ni tampoco entiende que la moral positiva sea intrínsecamente valiosa, por lo que la coacción jurídica sería el medio idóneo para su protección. Tampoco confunde la legitimidad democrática con la corrección moral de sus decisiones. Opta, más bien, por defender una tesis moderada: como la moral positiva es instrumentalmente valiosa para la integración social, debe ser protegida jurídicamente.

\section{III}

\section{La tesis de Hart}

Para Hart el problema del moralismo legal no es simplemente un problema acerca de la moral, sino un problema moral. Teniendo en cuenta la distinción entre la moral positiva y la moral crítica, el problema de la legislación moral debe responder desde la moralidad crítica acerca de la coacción de la moral positiva. Es decir, debe ofrecer argumentos que justifiquen o rechacen la imposición coactiva de la moral social. La discusión versa sobre si el principio del moralismo legal es bueno para penalizar conductas. La cuestión consiste en saber qué tipo de moralidad crítica debería adoptarse para legislar: o bien una que incluya el principio del moralismo legal, o bien otra que lo excluya. De manera que la discusión versa sobre la moralidad política crítica, no sobre los contenidos de la moral positiva ni sobre las normas para evaluar las morales críticas. Yo puedo discrepar con alguien acerca de los contenidos de su moral, y sin embargo coincidir con él acerca de los criterios para imponer una moral determinada.

La tesis de Hart viene a decir que la inmoralidad de una conducta juzgada como tal por la moral positiva no constituye una razón adecuada para legislar en su contra. La coacción legal, al limitar la libertad, exige una justificación que va más allá de la simple constatación de que una conducta transgreda la moral social. No siempre se ha argumentado a favor del moralismo legal, basándose en los mismos principios: a veces se ha sostenido que es un deber del Estado la búsqueda

ficadas por carecer de valor alguno para la formación de la opinión pública sobre el asunto de interés general que es objeto de la información. Esto es lo que afirma la sentencia del Tribunal Constitucional 171/1990, de 5 de noviembre. En el mismo sentido, la 214/1991, de 11 de noviembre, y la 219/1992, de 3 de diciembre, entre otras. 
de la perfección moral de sus ciudadanos, por lo que debe imponer coactivamente la moral social. Parece discutible no sólo la aceptación de la finalidad perfeccionista del Estado, sino también pensar que el mejor instrumento para conseguirlo consiste en imponer la moral positiva. Al menos, desde un punto de vista liberal, ni el fin, ni el medio, podrían aceptarse. Otras veces se ha defendido el valor intrínseco de la moral positiva, por lo que también se ha atribuido un valor intrínseco a la coacción legal que logra imponerla. La coacción legal sería valiosa como medio para mantener la moral positiva. Junto a esta tesis extrema, otros puntos de vista han defendido el moralismo legal desde posiciones más moderadas. La idea errónea de que la lealtad a la democracia implica el populismo moral ha conducido a decir que la mayoría tiene derecho a dictar cómo debemos todos, confundiendo la vox populi con la vox Dei. El procedimiento democrático no garantiza la bondad moral de sus resultados.

La tesis de Devlin es algo más moderada: sostiene que la moral positiva es instrumental mente valiosa para la integración social, lo cual justifica su imposición coactiva. Es cierto que toda sociedad requiere un mínimo de consenso moral para su propia existencia. De manera que cuando Devlin sostiene la necesidad de una moral reconocida para la existencia de una sociedad, está confundiendo algo razonable. Lo que no se puede hacer es, de la proposición que sostiene que alguna moral compartida es esencial para la existencia de una sociedad, deducir que una sociedad debe identificarse con su moral social histórica. Devlin sostiene que si no se produce tal identificación, la sociedad tiende a su autodestrucción: los cambios en la mentalidad moral son vistos como procesos desintegradores y destructivos.

Decir que la moral es esencial para la existencia de la sociedad es un enunciado ambiguo. Se puede dar a entender, al menos, dos cosas: se puede sostener que ciertas creencias morales son esenciales para la existencia de cualquier sociedad, o bien que ciertas creencias morales son esenciales para ciertos tipos de sociedad. La primera alternativa nos lleva a las procelosas aguas del contenido mínimo moral que una organización social debe tener para conservar su propia existencia como factor de coordinación y convergencias de conductas. La segunda nos lleva a precisar características morales deben tener los distintos tipos de sociedades que han existido y que conocemos, desde las primeras formas de matriarcado hasta las sociedades postcapitalistas. Ahora bien, si las sociedades cambian las creencias morales, aunque a veces los dos procesos no siguen el mismo ritmo. Lo que no tiene sentido decir es que los cambios sociales y morales contribuyen a desintegrar la sociedad: la identidad social es un proceso que se extiende a lo largo del tiempo, cuanto más la identidad de un grupo en el que convergen identidades personales diferentes y procesos de cambio 
complejos. Además, de la proposición de que las sociedades tienen su moral y el Estado el deber de protegerla, no se deriva que el Estado debe defender todos los prejuicios morales de la mayoría, incluso contra la opinión de los afectados, sino más bien el de defender esos espacios de libertad privados, a partir de los cuales es posible el progreso moral de la colectividad. Basta que concibamos la sociedad y la moral como algo cambiante, para que el papel del Estado, de defensor de la sociedad, se convierta en defensor de las formas cambiantes de la sociedad, es decir, de las fuentes del cambio moral.

Ahora bien, no se puede imputar a Devlin la tesis de que un simple cambio social contribuye a la desintegración de la sociedad. La percepción crítica de que un cambio en ciertas estructuras o creencias morales tiene consecuencias negativas para el conjunto de la sociedad se ha de basar, a su vez, en ciertos principios de moralidad crítica que justifican o desaprueban tal cambio. No se condena al cambio por el cambio, sino por los efectos que puede producir en la modificación de ciertos valores sustantivos.

No obstante, Devlin propone coaccionar la moral positiva, cualquiera que sea: acepta el principio de moralidad crítica de que es necesario la coacción de la moral positiva para legislar.

Hart, como representante de la tradición liberal, acepta la tesis antimoralista, aunque también sostiene la necesidad de bases positivas que fundamentan la legislación penal. El liberalismo tradicional y ortodoxo que sigue a Mill ha defendido el principio del daño a terceros. Hart se separa de este principio en la medida que reconoce la posibilidad de que se puede producir daño más allá de este principio limitado. Hart acepta el principio paternalista -la posibilidad de prohibir o imponer una conducta cuya realización o no es mejor o beneficia a quien la debe llevar a cabo- y el principio basado en la ofensa a otros ( «offense principle») cuya formulación es más ambigua, aunque no se puede identificar con el moralismo. Trataré de precisar tales conceptos con el fin de ver si tal posición puede ser compatible con una defensa liberal de la sociedad y del Derecho, como un camino intermedio entre el liberalismo ortodoxo y el moralismo legal.

Devlin presenta algunos contraejemplos de tipos penales que sólo pueden justificarse si se acepta el principio del moralismo legal. Los contraejemplos se pueden agrupar en dos principios normativos y en ocho tipos penales. Los dos principios se podrían formular del siguiente modo: el consentimiento de la víctima no es una eximente y la culpabilidad moral es relevante en la fijación de la severidad de la pena. Sólo si se admite la tesis del moralismo legal, sostiene Devlin, tales principios, vigentes en la mayoría de los códigos penales, pueden estar justificados. Los ocho tipos penales serían: bigamia, crueldad con los animales, homosexualidad, aborto, sodomía, incesto, obscenidad 
y delitos relativos a la prostitución. Hart despliega la defensa de sus principios para intentar demostrar que otros argumentos, con independencia del moralismo legal, pueden ser suficientes para penalizar tales conductas. En realidad, la defensa de la tesis antimoralista puede tomar alguna de estas dos formas. O bien se niega simplemente que tales conductas puedan prohibirse (como por ejemplo sucede con la homosexualidad) o bien puede decirse que tales conductas pueden prohibirse de acuerdo con otros principios. Por ejemplo, para Hart, la homosexualidad y el aborto no deberían declararse ilegales. La prohibición de la crueldad hacia los animales, en cambio, se puede justificar por el principio del daño interpretado en el sentido de que pueda incluir el alivio del sufrimiento y no simplemente la prevención del daño a otros. El principio paternalista justifica el principio de que el consentimiento de la víctima no sea una eximente. La bigamia y la prostitución callejera podrían encontrar cierta condena en el principio de la ofensa, etc.

Hart introduce el principio del paternalismo para justificar que el consentimiento de la víctima sea una causa de exención de responsabilidad criminal. Sólo funciona como tal en el caso de que forme parte del tipo penal, como es el caso de la violación. En los demás casos, el principio paternalista es suficiente para justificar ciertas prohibiciones de conductas que, de otro modo, podrían producir perjuicios en las propias personas que las llevan a cabo. Aunque el paternalismo usa el Derecho para proteger a la gente de sus propios errores no es suficiente para coaccionar jurídicamente la moral positiva.

Lo que Devlin critica de Hart es que su adopción del paternalismo conduce prácticamente al moralismo legal. Para Devlin, los dos principios llevan a los mismos resultados prácticos.

Ahora bien, parece que los dos principios son conceptualmente distintos. El propósito del paternalismo es prevenir el daño físico o moral de los individuos. El moralismo no exige tal daño. En realidad, Hart está defendiendo una versión débil del paternalismo, en el cual la decisión del agente afectado no se manifiesta claramente voluntaria. La versión fuerte del paternalismo permite legislar contra la voluntad de una persona incluso si se ha manifestado con total libertad y con plena información. Mill aceptó un paternalismo débil al considerar que las personas podrían ser coaccionadas contra su voluntad si se demostraba su ignorancia acerca de un peligro evidente.

De otro modo, el principio de la ofensa viene a decir que alguna conducta puede declararse ilegal no porque sea inmoral (principio del moralismo legal), sino porque es ofensiva, indecente o perturbadora para otros. Con este principio se puede prohibir la bigamia, sin tener que recurrir al moralismo legal: ahora bien, ¿por qué se prohíbe la bigamia y no el adulterio? Porque la bigamia es un atropello -sostiene 
Hart- contra la sensibilidad religiosa, ya que se manifiesta en un acto público. Pero, ¿por qué se castiga la publicidad de una conducta (bigamia) y no otra conducta privada (adulterio) que, debido a su conocimiento, puede producir también la misma ofensa que la pública?

Realmente es difícil establecer una distinción nítida entre las consecuencias que se deriven del principio de la ofensa y las del moralismo legal. Sabemos que Mill fue muy reticente ante los argumentos basados en las «ofensas» como razones que justificaban responsabilidades jurídicas. Porque la prohibición legal de las ofensas puede producir un daño mayor que el que trata de evitar. Se puede reprimir la libertad de expresión, el principio de autonomía personal y la virtud de la tolerancia ante formas o modos de vida minoritarios. Y esto puede afectar a las propias bases de un sistema democrático.

En todo caso, el problema está en hacer compatible la autonomía personal y su libre manifestación con ciertas exigencias públicas. Como no es función del Derecho imponer la moral social, si la propia sociedad estima que es necesario oponerse a ciertas conductas o prácticas deberá hacerlo en su propio ámbito y con sus propios procedimientos persuasivos, no mediante la fácil delegación en el Derecho y su concluyente mecanismo de fuerza. 